\title{
A SIMPLE METHOD FOR DETECTING EARLY SIGNAL IN NATURE OF PROGRESSION OF COVID-19 IN INDIAN POPULATION
}

PRABIR CHAKRAVARTY, Ph.D

Former Scientist, Albert Einstein College of Medicine (Yeshiva University), 1300, Morris Park Avenue, Bronx, New York-10461.

Present Lockdown Address:

$123 / 2 / 2$ A, B. C. Road, Kolkata, 700034, India. 


\section{ABSTRACT}

COVID-19 (SARS-Cov-2) is spreading around the globe in a highly contagious manner. China has shown the way to halt the progression of the disease by totally sealing Wuhan from rest of china but they could not prevent community spread resulting in more than 4000 deaths in a short period of time. India, following example of china, ordered national Lockdown early on 23 March, 2020. But it is difficult to determine the transition Here we have changed the way we look at available data to detect an early onset of the effect of Lockdown. Here a simple method is described for the first time to determine at the earliest when a change is beginning to take effect after Lockdown on the progression/regression of the spread of novel COVID19 virus which could help to frame strategy for intervention to prevent community spread and save lives.

\section{KEYWORDS}

COVID; lockdown; progression; community; spread 


\section{INTRODUCTION}

The nCOVID-19 is a novel corona virus having its origin in Wuhan district of China in December 2019. Its spread in china and rest of the world has caused mayhem during the last 3 months all over the world bringing the entire world to its knees. Until date there is no vaccine or therapeutic agent developed against this highly infectious virus that spreads through human contact. That makes it imperative to work on prevention of its spread.

Coronaviruses are a large family of viruses, including those that cause "the common cold" in healthy humans. These viruses account for up to 30 percent of upper respiratory tract infections in adults. This outbreak of COVID-19 marks the third time in recent years and has emerged to cause severe disease and death in the human population.

The new coronavirus (nCOVID-19), is closely related to SARS, and its characteristic feature is long latency period before the typical flu-like fever, cough, and shortness of breath manifest. The people infected with this virus may not show any symptoms for up to two weeks, allowing them to pass it on to others in the meantime. This time the virus started its journey in Wuhan, China and spread like wild fire and took thousands of lives. Overwhelmed by the enormity of the disaster even WHO/UN along with China downplayed the spread of virus through human contact when it was brought to their notice in December by a group in Taiwan. As a result, the novel Corona virus was able to easily spread all over the world through international flights and lack of monitoring for the early virus-symptoms at the point of entry. 
The recent disaster has prompted a massive global effort to contain and slow its spread. Despite those efforts, over the last month the virus has begun circulating outside of China in multiple countries and territories and India happens to be one of them. However, the silver lining is China was able to contain the virus within Wuhan by cutting the chain and isolating people with COVID-19 and identifying $\&$ isolating those with possible exposure.

At present it is ravaging the entire western world and gradually getting a hold in the eastern hemisphere. According to the Centre for Disease Control, CDC, NIH, USA, it may be possible to contract the virus responsible for the current outbreak, COVD-19/SARS-CoV-2, by touching a surface or object with the virus on it and then touching your face. However, COVD-19/SARSCoV-2 is believed to mostly spread from person-to-person through respiratory droplets produced when an infected person coughs or sneezes.

However, during early stages of the infection, it is not possible to ascertain whether steps taken to contain the virus were adequate to prevent its spread among wider population, by just looking at number of infected people. Here, a simple method is provided for the first time to detect early the plausible signal from the available data which could predict the nature of spread vis a vis progression in Indian population. It is shown that by ascertaining the rate of increase in percent on regular intervals, could throw light on whether there is slow down (flattening of the curve) or exponential progression of the rate of infection $\&$ further fine tune future course of action.

METHODS AND RESULTS: The study was carried out on the data collected from the entire Indian population who were diagnosed as Coronavirus positive (nCOVD + ve) starting from March 03, 2020. 
Due to alarming nature of Disaster world-wide and to contain the spread of the virus in Indian population, The Hon'ble Prime Minister of India declared one day of 'Janata Curfew' on 22 March 2020, from 7AM to 9 PM bringing the country to a standstill. Due to unnerving situation all over India and different states showing diverse rate of positive cases, complete 'National Lockdown' was declared for 21 days starting from 23rd Midnight to run until 14 April, 2020. From 9 PM of 22 March to 23 $3^{\text {rd }}$ Midnight there was temporary suspension of curfew. All data is available in public domain.

The Figure 1 shows the number of positive cases of COVID-19 until March 30, 2020. The number was collected at 10 PM each day from National news agencies \& other sources. It is reflected from the graph that there was a gradual increase in the number of nCOVID-19 +ve cases and as of 30 March 2020, there were 1263 cases in the entire country. However it is not possible to predict the trajectory of infection, effect of suspension of 'Janata Curfew' $\&$ the possible effect of Lockdown, if any on the rate of infection and whether further steps were warranted to stop its spread among population. In order to overcome such hurdles, the percent in increase of nCOVID-19+ve cases was tried. The results obtained from this study were startling \& introspective and are given in Figure: 2. The figure provides positive information regarding the effect of Curfew/'Lockdown' on the progression of nCOVID-19 infection in the Indian population. It is clear from the figure that from 24 March 2020 that is, after completion of the 'Janata curfew' there was a drastic decrease in percent of cases with nCOVID-19 +ve infection and the decrease in percentage points was being maintained stably during the period of National Lockdown' until writing this report, suggesting there was 
no community spread of the virus. Another interesting observation that came out was that in spite of nearly 24 hours gap between end of curfew and beginning of Lockdown the disruption in the chain of viral spread was not repaired. The same trend was maintained in percentage of infection as of 5 April, 2020.

\section{DISCUSSION:}

The COVID-19 is a dangerous disease because of its community spread through human contact (stage-3) wherein thousands are infected in an exponential manner and subsequently the available medical facilities are not adequate to deal with the enormity of the crisis resulting in huge number of death as observed in the USA, Italy \& now Spain. Therefore, availability of an early warning regarding the nature of spread nCOV-19, could effectively prepare the medical fraternity of an effected area, to be prepared to combat the disaster. The data presented in this paper clearly indicates that: a) Complete Lockdown is a correct approach to prevent human contact and break the chain of spread; b) An early signal could be obtained by plotting a simple graph depicting the percent increase/decrease in number of positive cases after introduction of stringent measures to prevent community spread c) A small time gap in between Curfew and Lockdown did not nullify advantage obtained in breaking the chain of spread \& d) The population study also reflected that age does not affect the rate of infection by nCOVID19.

There is a wrong perception among general population that younger population is less effected by the infection with novel COVID-19 as their immune response is better than 'older' individuals. Studies in South Korea 
and now in Iceland and Netherlands has destroyed the myth and has shown that younger people are equally vulnerable to nCOVID-19 infection (Figure: 3). The same trend was also maintained in the Indian population where there is maximum percentage of coronavirus effected persons were in the age group of 21-40 (42\%) as of $5^{\text {th }}$ April 2020 (Figure-4).

Immune response to COVID-19: Recently, Melbourne researchers have mapped immune responses from one of Australia's COVID-19 patients, showing the body's ability to fight the virus and recover from the infection. This suggested that the patient's body had been using many different "weapons" effectively against the new virus. The "influenza like immune response" started on $3^{\text {rd }}$ day of appearance of symptoms. The response involved increase in IgG, IgM up to 20 days $\&$ from $7^{\text {th }}$ day there was an increase in number of specialized helper \& Killer T cells \& B cells; showing body's ability to fight the virus and recover from the infection, notes Dr. Nguyen.

Vaccination against nCOVID-19: Several studies are underway in the USA and elsewhere to develop a vaccine. A first clinical trial in the U.S.A. to evaluate an experimental treatment for COVID-19 is already underway at the University of Nebraska Medical Center's bio-containment unit [1]. The NIH-sponsored trial will evaluate the safety and efficacy of the experimental antiviral drug remdesivir in hospitalized adults diagnosed with COVID-19.

One thing is clear from the present research that vaccination is yet to come and until then prevention is only the way to stay safe by avoiding human to human contact, at any cost and detect early the nature of spread of the virus. Following on the wisdom of Albert Einstein who believed that for every problem there is a 'simple solution' but 'don't make it simpler!'. Perhaps this 
study shows that by changing the way of looking at data wealth of information could be obtained which could be implemented to curb the spread. Not implementing harsh measures at the appropriate time could spell doom to human survival.

\section{References:}

1. NIH clinical trial of remdesivir to treat COVID-19 begins NIH News Release. Feb 25, 2020.

\section{Acknowledgement:}

1. Government of India for providing the data

2. Different News channels of India

3. Thanks to Dr. Prabal Chakravarty to assist me in preparation of Manuscript and for encouragment.

\section{LEGENDS TO FIGURES}

Figure:1 The graph shows the number of Corona virus positive individuals in Indian Population at different time points. There is a gradual increase in number of positive cases starting from 14 March until 30 March 2020. 
FIGURE: 2 The graph shows the percent of Corona Virus positive individuals from 23 March, 2020 until 30 March, 2020. The graph is intended to show the effect of 'janata Curfew' and 'Lockdown' on the progression. It is clear that there was 'flattening' of the curve after 'Janata Curfew' which was maintained until 30 March 2020. There was slight drop on 30 March 2020 compared to 29 March 2020 suggesting that a second phase of slowdown in spread started on the $6^{\text {th }}$ day of Lockdown.

FIGURE:3 The graph shows that age is not a criteria for spreading of novel corona virus among a given population ruling out the role of immune response during spread of the disease.

FIGURE: 4 The graph shows the distribution of corona virus infection in Different age groups within the population. The result reflects that people in the age group of 21-40 years have maximum rate of infection (42\%).

FIGURES FROM 1-4 
NUMBER OF COVID-19 POSITIVE PERSONS BETWEEN 13 MARCH-30 MARCH 2020

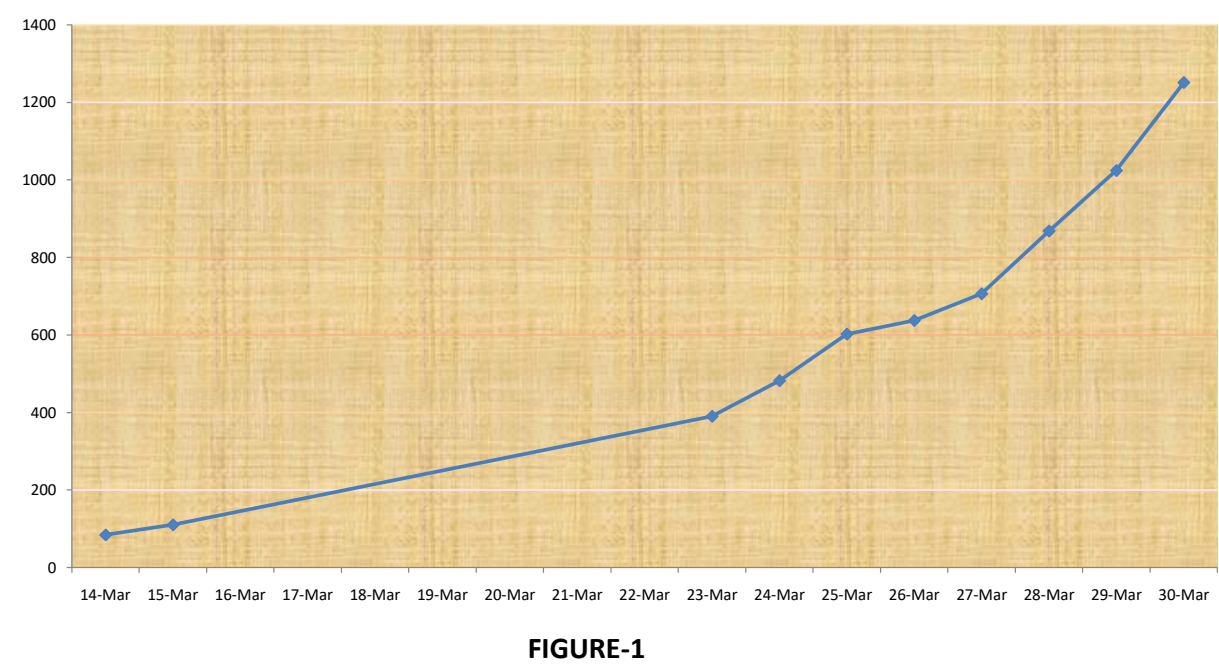




\section{PERCENT DIFFERENCE IN nCOVID-19 INFECTION AFTER LOCKDOWN}

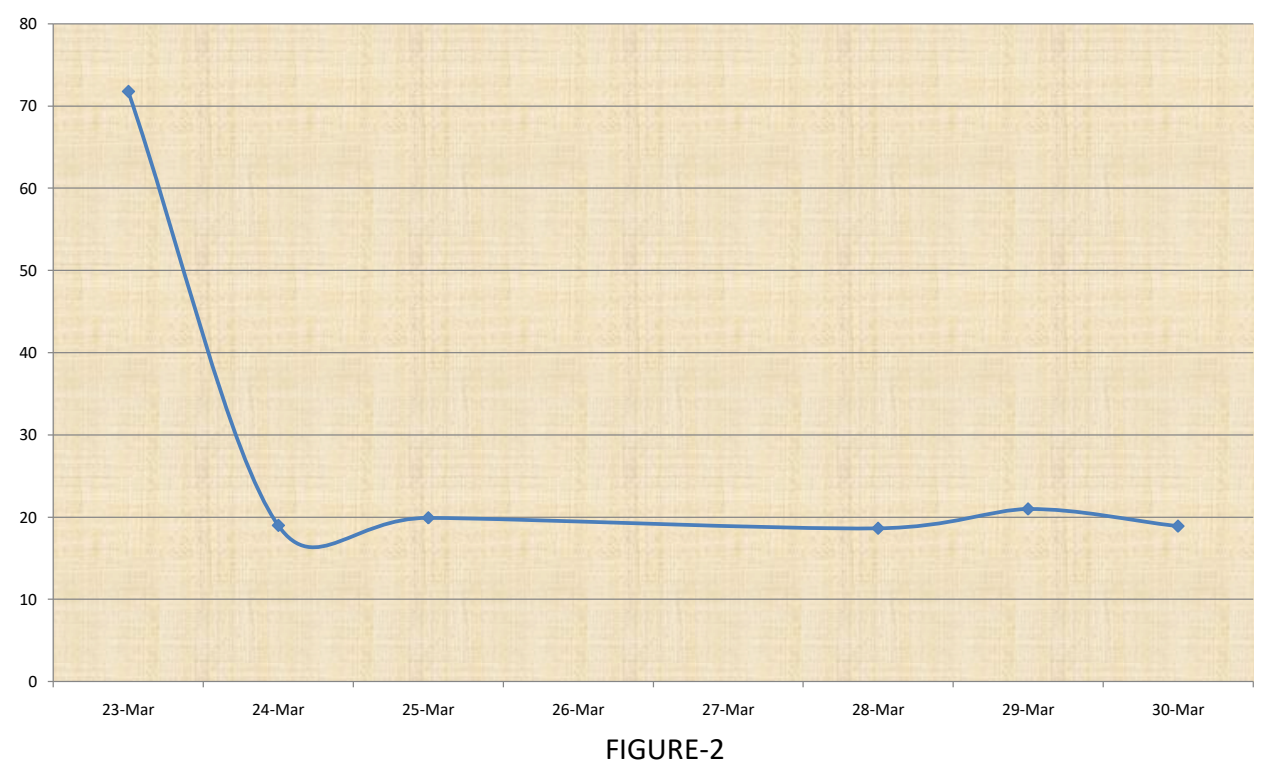




\section{Distribution of declared Covid-19 cases in Iceland and the Netherlands, by age group}

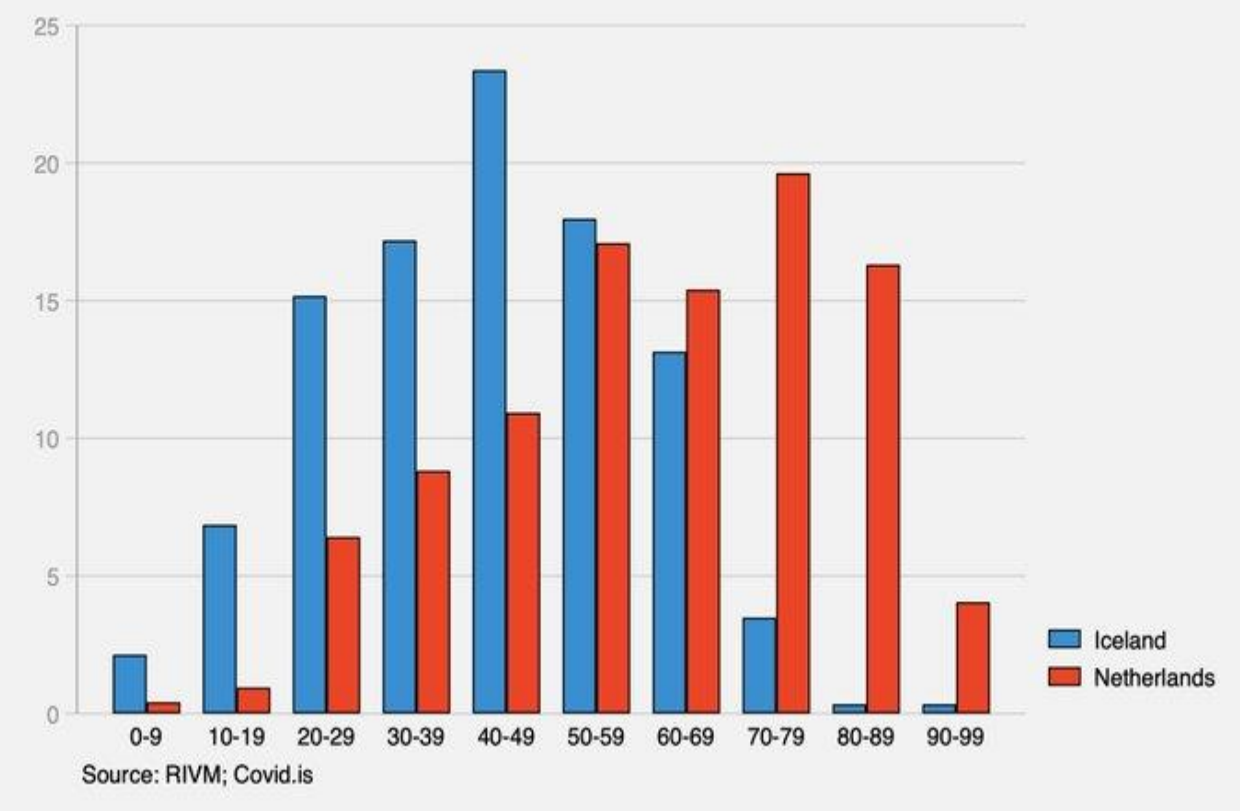

FIGURE-3 
DISTRIBUTION OF COVID-19 CASES IN INDIAN POPULATION BY AGE GROUP

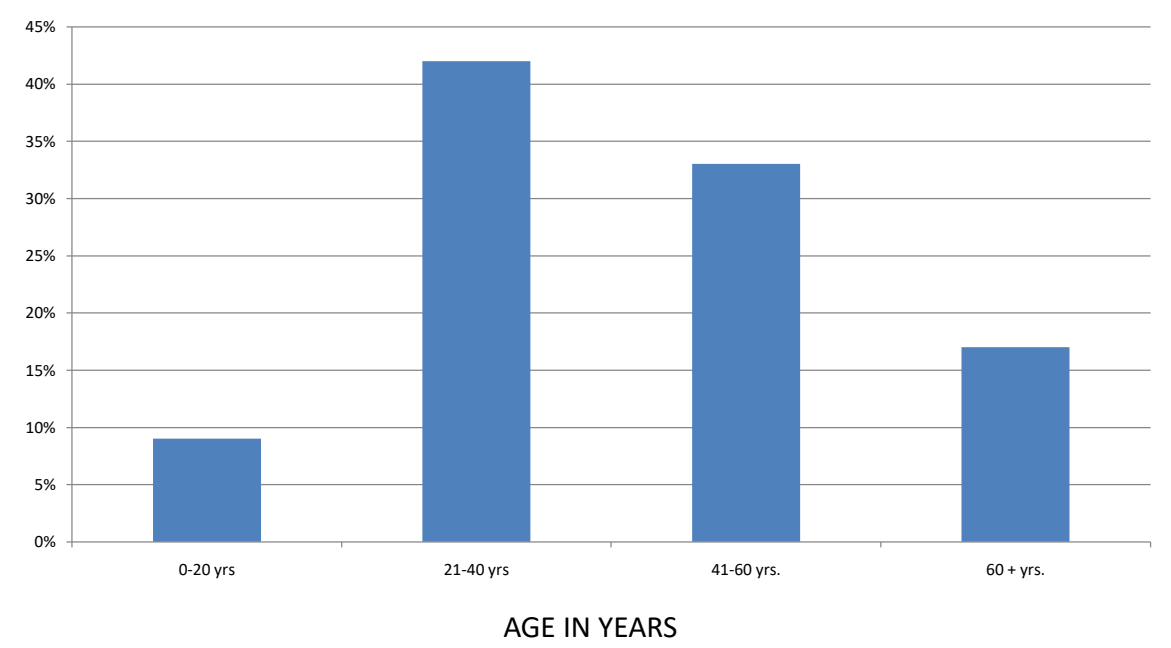

FIGURE: 4 